\title{
Circuit model of medical equipment for electrical safety purposes
}

\author{
E. Zennaro ${ }^{1}$, C. Mazzetti ${ }^{1}$, F. Fiamingo ${ }^{2}$ \& G. L. Amicucci ${ }^{2}$ \\ ${ }^{1}$ Department of Astronautics, Electrical and Energetics Engineering \\ (DIAEE), Sapienza Università di Roma, Italy \\ ${ }^{2}$ Department of Safety Technologies (DTS), Istituto Nazionale per \\ l'Assicurazione contro gli Infortuni sul Lavoro (INAIL), Italy
}

\begin{abstract}
In order to assess the risk of electric shock during a surgical procedure, it's important to know the insulation paths and the values of the insulation impedances of Medical Electrical (ME) equipment and then to draw "leakage circuits" and monitor the intensity of "leakage currents".

The aim of this work is to propose a circuit based model of a ME equipment to simulate the leakage currents measured during electrical safety tests. The setup of these measures are described in the standard EN 60601-1, which also describes the insulations composing a ME equipment and where they are placed. While the standard EN 62353 describes the insulation resistances should be measured. This information is the references for the model development which is subsequently implemented with the circuit simulation software National Instruments Multisim. The application of the circuit model allows the simulation of an earth leakage current, touch current and patient leakage current similar to real equipment, both in normal and in single fault conditions. The values of the electrical parameters of the model from a measurement report of a commercial defibrillator are assigned. The results of circuit model leakage currents are compared with the measurement data. The output of this comparison may be considered quite satisfactory. In this paper the extension of the model to other ME equipment is also discussed in view of the assessment of the risk of electrical shock during a surgical procedure.
\end{abstract}

Keywords: microshock risk, medical equipment, circuit model of the defibrillator, floating type applied part, risk analysis, electrical safety. 


\section{Introduction}

Healthcare facilities are critical infrastructures where safety of patients and medical operator must be ensured. The mutual relationship between the ME equipment, the patient, the health personnel and the related environment needs to be carefully considered because of the health status of the patient. In some medical procedures, low current is sufficient to cause respiratory paralysis $(\approx 10 \mathrm{~mA})$ or potentially fatal ventricular fibrillation $(\approx 20 \mathrm{~mA})$. The low resistance pathway via skin penetration and the decreased patient defences because of anesthesia, increase the risk of electric shock under faulty condition, as reported by Amicucci et al. [1].

For the purpose of risk analysis in a surgical room information is required about the power system installed into the medical structure, as well as technical data of ME equipment. But the leakage currents from every ME equipment used during the surgical procedure, the values of their insulation impedances and the insulation paths through which currents flow, are often not available.

The standard ISO/DIS 13824 [2] considers the use of engineering models to estimate the risk of a system where data are lacking. Corbellini [3] suggested the use of software for the simulation and modelling. Spalding et al. [4] shows an electrical model of a ME equipment supplied from an IT-M distribution system to explain how detect and measure the microshock risk by computer simulations and hardware equipment.

In this paper a novel approach is presented to evaluate the leakage currents from real ME equipment tested in accordance with standards CEI EN 60601-1 $2^{\text {nd }}$ ed. [5] and CEI EN 62353 [6]. In particular the layout and the electrical parameters values of the circuit model are presented.

\section{Circuit model}

The two last editions of standard CEI EN 60601-1 [5, 7] have constituted the key publications of reference for modelling the circuit shown in Fig. 1. The older edition of such standard specifies the construction details, as the type of insulation and where this should be placed. While the newer edition specifies the limit values of leakage currents and specifies the measurement set-up to evaluate whether they are exceeded from the equipment under test. Moreover standard CEI EN 62353 [6] is also important to understand how many insulations should be calculated for the leakage current estimation. It requires that insulation resistance shall be measured at voltage of $500 \mathrm{~V}$ dc between:

a) the mains part and protective earth for class I equipment;

b) the mains part and (non-earthed) accessible conductive parts for class I and class II equipment;

c) the mains part and the applied parts;

d) floating type applied part and protective earth for class I equipment;

e) floating type applied part and (non-earthed) accessible conductive parts for class I and class II equipment. 
During the operation, the frequency of electrical equipment is equal to $50 \mathrm{~Hz}$ in Europe and insulation should be modelled with an ohmic-capacitive parallel impedance. In fact when frequency is not null, capacitance ("insulation capacitance" in the paper) reduces impedance and increases current that flow over the equipment through the earth or the patient.

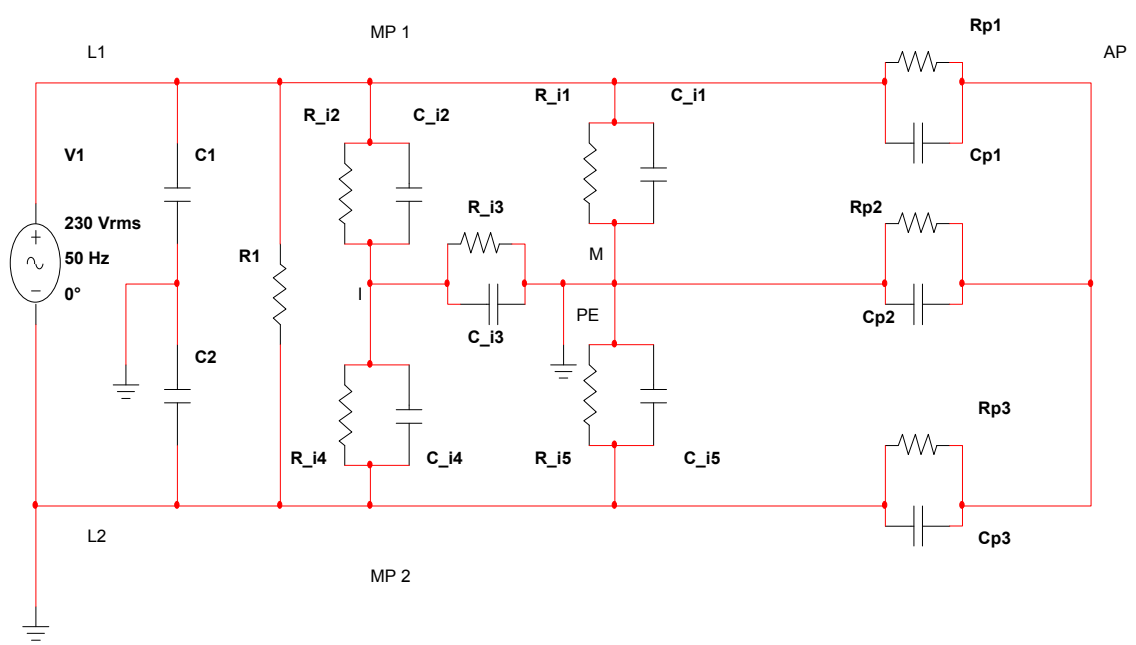

Figure 1: Electrical circuit model of the generic ME equipment with floating (F) type applied part.

Fig. 1 shows the phase-neutral with floating (F) type applied part circuit model of a generic ME equipment. It follows the explanation of the circuit parameters:

- $M P$ : mains part or alive part;

- I: enclosure;

- M: ground;

- $A P$ : applied part;

- L1: supply phase L1 (one of the two alive parts);

- L2: supply phase L2 (the other of the two alive parts);

- V1: root mean square value of the supply voltage of the ME equipment. The value is equal to $230 \mathrm{~V}$ and the frequency is equal to $50 \mathrm{~Hz}$;

- C1, C2: electromagnetic interference (EMI) filter capacitances;

- R1: ME equipment resistive load which absorbs electrical power;

- Ri1, Ci1 and Ri5, Ci5: basic insulation between alive parts and conductive accessible parts that are protectively earthed (named "ground" in the paper);

- Ri2, Ci2 and Ri4, Ci4: double insulation or reinforced insulation between alive parts and conductive accessible parts non-protectively earthed (named "enclosure" in the paper), for example moving parts for 
which PE connection is not recommended due to its poor reliability (in general for class II equipment);

- Ri3, Ci3: insulation between ground and enclosure. It is indicated in [5] that this insulation would be in addition to the insulations interposed to alive parts;

- Rp1, Cp1 and Rp2, Cp2 and Rp3, Cp3: insulations between applied part and one of the two supply phases, applied part and conductive accessible part, applied part and the other of the two supply phases respectively.

The circuit model described in Fig. 1 allows us to simulate leakage currents similar to that of a real equipment. It has been successful applied in the case of a commercial defibrillator. In Fig. 2 the electrical diagram of commercial defibrillator for electric safety measurements in an Italian hospital is presented. The diagram is drawn on the software platform National Instruments Multisim, which is particularly suitable to perform simulations.

The commercial defibrillator under test is a class I ME equipment, with a basic insulation between alive parts and ground. Touch current values measured during tests shows that all conductive accessible parts are protectively earthed. The defibrillator is composed by three cardiac floating (CF)-type applied parts and two body floating (BF)-type applied parts. The CF-type applied parts are ElectroCardioGraphic (ECG) electrodes ("electrodes" in the paper) and the BF-type applied parts are paddle electrodes ("paddles" in the paper) from which the electrical discharge is delivered. Fig. 2 shows the Measuring Device (MD) that is modelled as reported in [7] where the resistance of $1 \mathrm{k} \Omega$ represents the human body. So this circuit models a specific defibrillator put into operation on a laboratory bench to test earth leakage current, touch current and patient leakage current. These currents are measured in:

- normal condition (NC);

- when a supply conductor or the protective earth conductor are open (single fault conditions SFC);

both with normal supply polarity and reversed supply polarity. Defibrillator has not been placed in an operating room, where other electrical equipment as insulation transformers, supply lines, etc. would be modelled in addiction.

In Fig. 2 switches J1 and J3 are shown. They are drawn to simulate the inversion of supply polarity. Switch $\mathrm{J} 2$ is drawn to simulate disconnection of one supply phase while switch J4 simulates the disconnection of PE. The insulation between applied parts and alive parts can be double, or composed by basic insulation + secondary circuit protectively earthed, basic insulation + metallic shield or by impedances. The insulation between applied parts and conductive accessible parts can be solid considering creepage distances, or air considering air clearance.

Values of impedance and capacitance have been calculated by means of formulas (1), (2), (3) and (4). Resistance values are assigned by measurement tests listed in [6] and written as a), b), c), d) and e) at the beginning of this section. The EMI filter capacitance is assigned equal to $1 \mathrm{nF}$ which is a reasonable value and its variations don't influence the results of the model. 


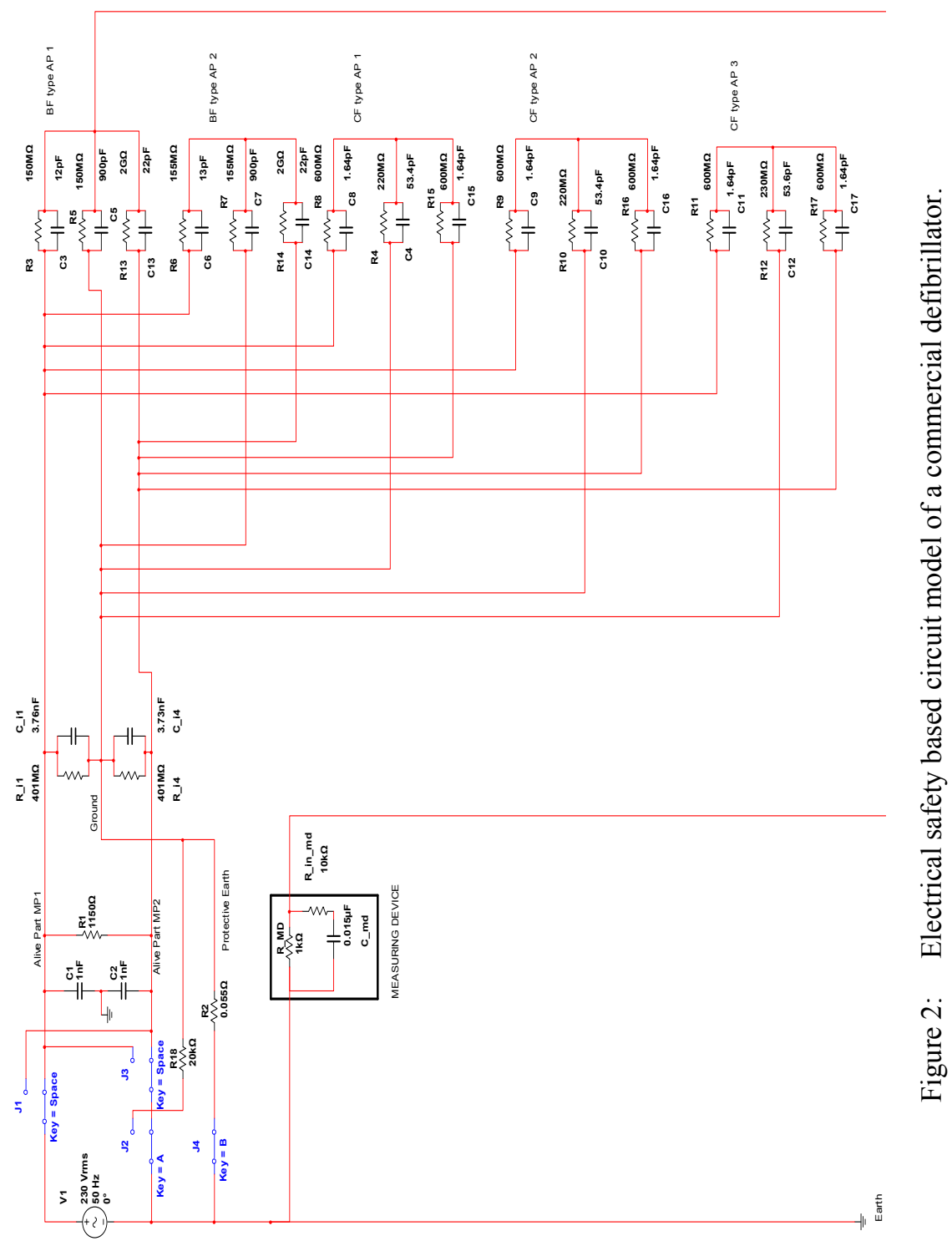




$$
\begin{gathered}
Z=\left(\frac{1}{R}+j \omega C\right)^{-1}=\frac{R}{1+j \omega C R} \Rightarrow \frac{R}{1+j \omega C R} \cdot \frac{1-j \omega C R}{1-j \omega C R}= \\
\frac{R}{1+(\omega C R)^{2}}-j \frac{\omega C R^{2}}{1+(\omega C R)^{2}}
\end{gathered}
$$

$$
C_{1,2}= \pm \sqrt{\frac{-\left(2|Z|^{2} \omega^{2} R^{2}-\omega^{2} R^{4}\right) \pm \sqrt{\left(2|Z|^{2} \omega^{2} R^{2}-\omega^{2} R^{4}\right)^{2}-4\left(\omega^{4} R^{4}|Z|^{2}\right)\left(|Z|^{2}-R^{2}\right)}}{2 \omega^{4} R^{4}|Z|^{2}}}
$$

The parameters of the circuit model are shown in Table 1.

It is important to note that insulation resistances between applied parts and alive parts are not measured during tests. Their values in the model are assigned on the basis of the leakage currents measured taking into account the accuracy range of the MD: $1 \%$ of read value $\pm 1 \mu \mathrm{A}$.

\section{Results}

The circuit model results of leakage current are compared with the measurement data obtained from tests carried using a commercial defibrillator.

It is important to note how the data returned by the model are in line with what was expected. In fact, the earth leakage current, the touch current and the patient leakage currents which flow through the circuit in single fault conditions are greater than those found in normal condition. While the measurement data show that there is no difference in the values of touch current and the patient leakage currents when a supply conductor is open compared to the normal condition. The range accuracy of the MD justifies the difference between the experimental data and simulated ones.

As it can be noticed, the simulated patient leakage currents from the paddles when a supply conductor is open are not twice the same currents in normal condition as it happen for the simulated patient leakage currents from the 
electrodes. Moreover, the values of these currents are slightly different when the polarity is reversed. The asymmetry values of the insulation impedances of the paddles with respect to the two alive parts, justifies this difference shown in the Table 2.

Table 1: Comparison between electrical parameter values measured on a commercial defibrillator and simulated ones.

\begin{tabular}{|c|c|c|}
\hline Electrical parameter & Real defibrillator & Simulated defibrillator \\
\hline Load resistance & $1150 \Omega$ & $1150 \Omega$ \\
\hline $\mathrm{PE}$ & $0.055 \Omega$ & $0.055 \Omega$ \\
\hline Basic insulation resistance & $\begin{array}{l}\text { OVER ( }>400 \mathrm{M} \Omega \text { maximum of } \\
\text { the MD measurement range) }\end{array}$ & $401 \mathrm{M} \Omega$ \\
\hline $\begin{array}{l}\text { Basic insulation } \\
\text { capacitance }\end{array}$ & unknown & $\begin{array}{c}3.76 \mathrm{nF} \text { with respect to the } \\
\text { phase L1 } \\
3.73 \mathrm{nF} \text { with respect to the } \\
\text { phase L2 }\end{array}$ \\
\hline $\begin{array}{l}\text { LL pad insulation } \\
\text { resistance with respect to } \\
\text { the ground }\end{array}$ & $150 \mathrm{M} \Omega$ & $150 \mathrm{M} \Omega$ \\
\hline $\begin{array}{l}\text { LL pad insulation } \\
\text { capacitance with respect to } \\
\text { the ground }\end{array}$ & unknown & $900 \mathrm{pF}$ \\
\hline $\begin{array}{c}\text { LL pad insulation } \\
\text { resistance with respect to } \\
\text { the alive parts }\end{array}$ & unknown & $\begin{array}{l}150 \mathrm{M} \Omega \text { with respect to } \mathrm{L} 1 \\
2 \mathrm{G} \Omega \text { with respect to } \mathrm{L} 2\end{array}$ \\
\hline $\begin{array}{c}\text { LL pad insulation } \\
\text { capacitance with respect to } \\
\text { the alive parts }\end{array}$ & unknown & $\begin{array}{l}12 \mathrm{pF} \text { with respect to } \mathrm{L} 1 \\
22 \mathrm{pF} \text { with respect to } \mathrm{L} 2\end{array}$ \\
\hline $\begin{array}{l}\mathrm{V} \text { pad insulation resistance } \\
\text { with respect to the ground }\end{array}$ & $155 \mathrm{M} \Omega$ & $155 \mathrm{M} \Omega$ \\
\hline $\begin{array}{l}\text { V pad insulation } \\
\text { capacitance with respect to } \\
\text { the ground }\end{array}$ & unknown & $900 \mathrm{pF}$ \\
\hline $\begin{array}{l}\text { V pad insulation resistance } \\
\text { with respect to the alive } \\
\text { parts }\end{array}$ & unknown & $\begin{array}{l}155 \mathrm{M} \Omega \text { with respect to } \mathrm{L} 1 \\
2 \mathrm{G} \Omega \text { with respect to } \mathrm{L} 2\end{array}$ \\
\hline $\begin{array}{c}\text { V pad insulation } \\
\text { capacitance with respect to } \\
\text { the alive parts }\end{array}$ & unknown & $\begin{array}{l}13 \mathrm{pF} \text { with respect to } \mathrm{L} 1 \\
22 \mathrm{pF} \text { with respect to } \mathrm{L} 2\end{array}$ \\
\hline $\begin{array}{l}\text { RA electrode insulation } \\
\text { resistance with respect to } \\
\text { the ground }\end{array}$ & $220 \mathrm{M} \Omega$ & $220 \mathrm{M} \Omega$ \\
\hline $\begin{array}{l}\text { RA electrode insulation } \\
\text { capacitance with respect to } \\
\text { the ground }\end{array}$ & unknown & $53.4 \mathrm{pF}$ \\
\hline $\begin{array}{l}\text { RA electrode insulation } \\
\text { resistance with respect to } \\
\text { the alive parts }\end{array}$ & unknown & $\begin{array}{c}600 \mathrm{M} \Omega \text { with respect to the } \\
\text { alive parts }\end{array}$ \\
\hline $\begin{array}{c}\text { RA electrode insulation } \\
\text { capacitance with respect to } \\
\text { the alive parts }\end{array}$ & unknown & $1.64 \mathrm{pF}$ \\
\hline
\end{tabular}


Table 1: Continued.

\begin{tabular}{|c|c|c|}
\hline Electrical parameter & Real defibrillator & Simulated defibrillator \\
\hline $\begin{array}{c}\text { RL electrode insulation } \\
\text { resistance with respect to } \\
\text { the ground }\end{array}$ & $220 \mathrm{M} \Omega$ & $220 \mathrm{M} \Omega$ \\
\hline $\begin{array}{c}\text { RL electrode insulation } \\
\text { capacitance with respect to } \\
\text { the ground }\end{array}$ & unknown & $53.4 \mathrm{pF}$ \\
\hline $\begin{array}{c}\text { RL electrode insulation } \\
\text { resistance with respect to } \\
\text { the alive parts }\end{array}$ & unknown & $600 \mathrm{M} \Omega$ with respect to the \\
alive parts
\end{tabular}

\section{Conclusions}

In this work we have shown the circuit model of a real ME equipment suitable for assessment of microshock risk.

The model contains all insulation resistances that are considered in standards CEI EN 60601-1 and CEI EN 62353. Values of model parameters may be obtained from electrical safety tests on the considered ME equipment and by simple application of Ohm's law, which allow to calculate resistances and capacitances that constitute insulation impedances.

The model simulates "leakage currents" from ME equipment in normal condition and in single fault conditions.

It has been validated by the application to a commercial defibrillator and results of simulated leakage currents are to be considered in quite satisfactory agreement taking into account the accuracy range of the MD used for tests.

The method presented to construct the circuit model of a ME equipment can be extended to draw the safety based model of any other ME equipment by assigning the values of insulation impedances from the results of laboratory tests, required by the regulations. In fact, even if $\mathrm{ME}$ equipment are physically much different, they must comply with the requirements of the standards. So, the model of each of the equipment is composed by insulations which are to be measured as is written in [6] and its leakage currents must comply with limit values as is reported in [7]. This does not exclude that in constructing the circuit model of a ME equipment is necessary to take into account its own 
particularities, for example the class of the electrical equipment or the number and the type of applied parts.

The modelling of ME equipment used in a surgical procedure is important to assess the risk of microshock in the operating room.

Table 2: $\quad$ Comparison between leakage current values measured during the electrical safety tests on a commercial defibrillator and simulated values from its electrical circuit model.

\begin{tabular}{|c|c|c|}
\hline $\begin{array}{l}\text { Device's component } \\
\text { Operating condition }\end{array}$ & Measured value $[\mu \mathrm{A}]$ & $\begin{array}{l}\text { Simulated } \\
\text { value }[\mu \mathrm{A}]\end{array}$ \\
\hline $\begin{array}{c}\mathrm{PE} \\
\text { Earth leakage current in normal condition }\end{array}$ & 274 & 274 \\
\hline $\begin{array}{c}\text { PE } \\
\text { Earth leakage current when a supply conductor is open }\end{array}$ & 522 & 518 \\
\hline $\begin{array}{c}\text { PE } \\
\text { Earth leakage current in normal condition and supply } \\
\text { polarity reversed }\end{array}$ & 273 & 273 \\
\hline $\begin{array}{c}\text { PE } \\
\begin{array}{c}\text { Earth leakage current when a supply conductor is open } \\
\text { and supply polarity reversed }\end{array} \\
\end{array}$ & 525 & 518 \\
\hline $\begin{array}{c}\text { Enclosure } \\
\text { Touch current in normal condition }\end{array}$ & 0 & 0.015 \\
\hline $\begin{array}{c}\text { Enclosure } \\
\text { Touch current when a supply conductor is open }\end{array}$ & 0 & 0.03 \\
\hline $\begin{array}{c}\text { Enclosure } \\
\text { Touch current when PE is open }\end{array}$ & 270 & 274 \\
\hline $\begin{array}{c}\text { Enclosure } \\
\text { Touch current in normal condition and supply polarity } \\
\text { reversed }\end{array}$ & 0 & 0.015 \\
\hline $\begin{array}{c}\text { Enclosure } \\
\text { Touch current when a supply conductor is open and } \\
\text { supply polarity reversed }\end{array}$ & 0 & 0.03 \\
\hline $\begin{array}{c}\text { Enclosure } \\
\text { Touch current when PE is open and supply polarity } \\
\text { reversed }\end{array}$ & 273 & 273 \\
\hline $\begin{array}{c}\text { Electrode RA } \\
\text { Patient leakage current in normal condition }\end{array}$ & 0 & 0.4 \\
\hline $\begin{array}{c}\text { Electrode RA } \\
\text { Patient leakage current when a supply conductor is open }\end{array}$ & 0 & 0.8 \\
\hline $\begin{array}{c}\text { Electrode RA } \\
\text { Patient leakage current when PE is open }\end{array}$ & 2 & 2.23 \\
\hline $\begin{array}{c}\text { Electrode RA } \\
\text { Patient leakage current in normal condition and supply } \\
\text { polarity reversed }\end{array}$ & 0 & 0.4 \\
\hline $\begin{array}{c}\text { Electrode RA } \\
\text { Patient leakage current when a supply conductor is open } \\
\text { and supply polarity reversed }\end{array}$ & 0 & 0.8 \\
\hline $\begin{array}{l}\text { Electrode RA } \\
\text { Patient leakage current when PE is open and supply } \\
\text { polarity reversed }\end{array}$ & 2 & 2.22 \\
\hline $\begin{array}{c}\text { Electrode RL } \\
\text { Patient leakage current in normal condition }\end{array}$ & 0 & 0.4 \\
\hline $\begin{array}{c}\text { Electrode RL } \\
\text { Patient leakage current when a supply conductor is open }\end{array}$ & 0 & 0.8 \\
\hline
\end{tabular}


Table 2: $\quad$ Continued.

\begin{tabular}{|c|c|c|}
\hline $\begin{array}{l}\text { Device's component } \\
\text { Operating condition }\end{array}$ & Measured value $[\mu \mathrm{A}]$ & $\begin{array}{l}\text { Simulated } \\
\text { value }[\mu \mathrm{A}]\end{array}$ \\
\hline $\begin{array}{c}\text { Electrode RL } \\
\text { Patient leakage current when PE is open }\end{array}$ & 2 & 2.23 \\
\hline $\begin{array}{c}\text { Electrode RL } \\
\text { Patient leakage current in normal condition and supply } \\
\text { polarity reversed }\end{array}$ & 0 & 0.4 \\
\hline $\begin{array}{c}\text { Electrode RL } \\
\begin{array}{c}\text { Patient leakage current when a supply conductor is open } \\
\text { and supply polarity reversed }\end{array}\end{array}$ & 0 & 0.8 \\
\hline $\begin{array}{c}\text { Electrode RL } \\
\text { Patient leakage current when PE is open and supply } \\
\text { polarity reversed }\end{array}$ & 2 & 2.22 \\
\hline $\begin{array}{c}\text { Electrode LA } \\
\text { Patient leakage current in normal condition }\end{array}$ & 0 & 0.4 \\
\hline $\begin{array}{c}\text { Electrode LA } \\
\text { Patient leakage current when a supply conductor is open }\end{array}$ & 0 & 0.8 \\
\hline $\begin{array}{c}\text { Electrode LA } \\
\text { Patient leakage current when PE is open }\end{array}$ & 2 & 2.23 \\
\hline $\begin{array}{c}\text { Electrode LA } \\
\text { Patient leakage current in normal condition and supply } \\
\text { polarity reversed }\end{array}$ & 0 & 0.4 \\
\hline $\begin{array}{c}\text { Electrode LA } \\
\begin{array}{c}\text { Patient leakage current when a supply conductor is open } \\
\text { and supply polarity reversed }\end{array} \\
\end{array}$ & 0 & 0.8 \\
\hline $\begin{array}{c}\text { Electrode LA } \\
\text { Patient leakage current when PE is open and supply } \\
\text { polarity reversed }\end{array}$ & 2 & 2.22 \\
\hline $\begin{array}{c}\text { Paddle LL } \\
\text { Patient leakage current in normal condition } \\
\end{array}$ & 2 & 1.76 \\
\hline $\begin{array}{c}\text { Paddle LL } \\
\text { Patient leakage current when a supply conductor is open }\end{array}$ & 2 & 2.96 \\
\hline $\begin{array}{c}\text { Paddle LL } \\
\text { Patient leakage current when PE is open }\end{array}$ & 30 & 30.1 \\
\hline $\begin{array}{c}\text { Paddle LL } \\
\begin{array}{c}\text { Patient leakage current in normal condition and supply } \\
\text { polarity reversed }\end{array}\end{array}$ & 2 & 1.59 \\
\hline $\begin{array}{c}\text { Paddle LL } \\
\begin{array}{c}\text { Patient leakage current when a supply conductor is open } \\
\text { and supply polarity reversed }\end{array}\end{array}$ & 2 & 2.96 \\
\hline $\begin{array}{c}\text { Paddle LL } \\
\begin{array}{c}\text { Patient leakage current when PE is open and supply } \\
\text { polarity reversed }\end{array}\end{array}$ & 31 & 30.6 \\
\hline $\begin{array}{c}\text { Paddle V } \\
\text { Patient leakage current in normal condition }\end{array}$ & 2 & 1.76 \\
\hline $\begin{array}{c}\text { Paddle V } \\
\text { Patient leakage current when a supply conductor is open }\end{array}$ & 2 & 2.99 \\
\hline $\begin{array}{c}\text { Paddle V } \\
\text { Patient leakage current when PE is open }\end{array}$ & 30 & 30.1 \\
\hline $\begin{array}{c}\text { Paddle V } \\
\begin{array}{c}\text { Patient leakage current in normal condition and supply } \\
\text { polarity reversed }\end{array}\end{array}$ & 2 & 1.59 \\
\hline $\begin{array}{c}\text { Paddle V } \\
\begin{array}{c}\text { Patient leakage current when a supply conductor is open } \\
\text { and supply polarity reversed }\end{array} \\
\end{array}$ & 2 & 2.99 \\
\hline
\end{tabular}




\section{Acknowledgement}

The authors are grateful to Giacomo Fazi for his valid support during the model development and literature search.

\section{References}

[1] Amicucci, G. L., Di Lollo, L., Fiamingo, F., Mazzocchi, V., Platania, G., Ranieri, D., Razzano, R., Camin, G., Sebastiani, G., Gentile, P., Electrical safety during transplantation. Transplantation Proceedings, Elsevier, 42, pp. 2175-2180, 2010.

[2] ISO/DIS 13824 "General principles on risk assessment of systems involving structures" 2008.

[3] Corbellini, G., Impianti elettrici - sicurezza elettrica nei locali adibiti ad uso medico e chirurgico, vol. 4 part. 1, La Goliardica Pavese, 1999.

[4] Spalding, L., Carpes, W. Jr., Batistela, N., A method to detect the microshock risk during a surgical procedure. IEEE Transactions on Instrumentation and measurement, 58(7), pp. 2335-2342, 2009.

[5] CEI EN 60601-1 "Medical electrical equipment - General requirements for safety" 2nd ed., 1998.

[6] CEI EN 62353 "Medical electrical equipment - Recurrent test and test after repair of medical electrical equipment", 2008.

[7] CEI EN 60601-1 "Medical electrical equipment - General requirements for basic safety and essential performance" 3rd ed. 2007. 